\title{
Prolactin Concentrations in Patients with Breast Cancer
}

\author{
S. FRANKS, D. N. L. RALPHS, VALERIE SEAGROATT, H. S. JACOBS
}

British Medical fournal, 1974, 4, 320-321

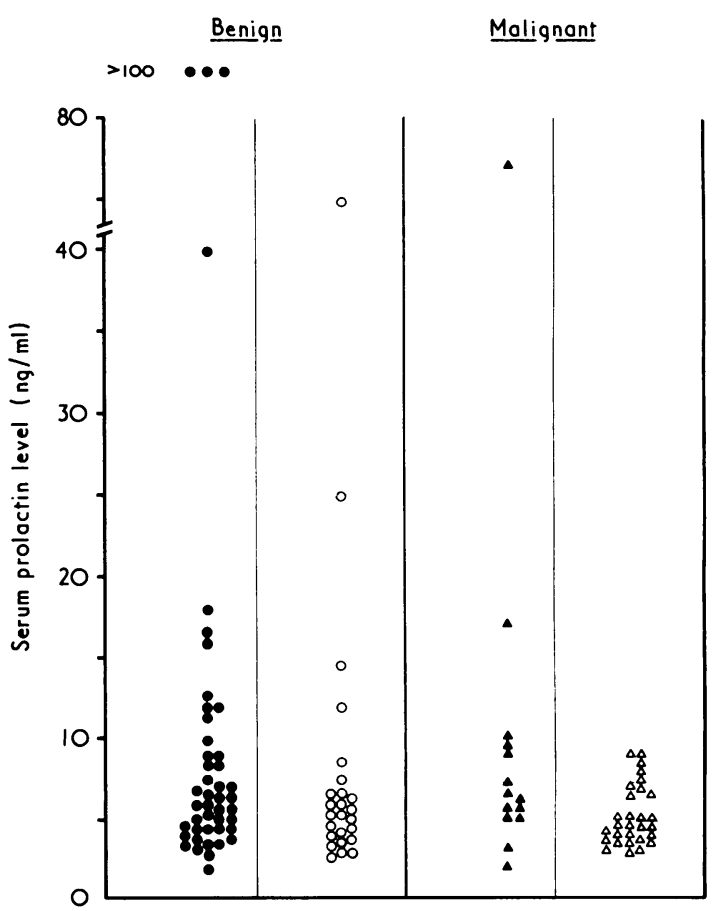

\begin{abstract}
Summary
Basal prolactin levels were measured before operation in 113 patients undergoing surgery for a lump in the breast. Prolactin concentrations were not significantly higher in those patients with breast cancer than in those with benign lumps. Prolactin concentrations were, however, found to be higher in premenopausal women than in postmenopausal ones, regardless of tumour histology.
\end{abstract}

\section{Introduction}

Considerable speculation surrounds the relationship of prolactin secretion to breast cancer (Lancet, 1974). There are reports of both normal (Bucken et al., 1973; Mittra et al., 1974) and raised (Murray et al., 1972) prolactin concentrations in patients with malignant tumours of the breast. We report here the basal serum prolactin concentrations in a group of patients with cancer of the breast and a comparison of these results with those obtained in women undergoing surgery for what subsequently proved to be benign lesions of the breast.

\section{Patients and Methods}

Blood samples were obtained one or two days before operation in a group of 113 inpatients undergoing surgery for a lump in the breast. The diagnosis in all cases was based on histological examination of the excised lesion. Blood samples were allowed to clot at room temperature for two hours and after centrifugation the serum was removed and stored at $-20^{\circ} \mathrm{C}$ until assayed. Prolactin was measured by radioimmunoassay (Sinha et al., 1973) using reagents kindly supplied by the Hormone Distribution Programme of the National Pituitary Agency of the National Institute for Arthritis, Metabolic, and Digestive Diseases. The results were expressed in terms of human prolactin (National Pituitary Agency standard V.-L.-S. 1). The mean prolactin concentration $( \pm 1$ S.D.) in 50 normal women was $6.5 \pm 4.0 \mathrm{ng} / \mathrm{ml}$, and in this group we found no significant difference in prolactin concentrations between premenopausal and postmenopausal women

\section{Results}

The prolactin concentrations in the 113 patients are shown in the fig. The results were grouped according to the histological report (benign or malignant) and according to the reproductive status (premenopausal or postmenopausal). Visual inspection of data suggested that there may have been a difference in the

Department of Nuclear Medicine, Institute of Clinical Science, Middlesex Hospital Medical School, London W1

S. FRANKS, M.B., M.R.C.P., Saltwell Research Fellow

VALERIE SEAGROATT, M.SC., Research Assistant

Middlesex Hospital, London W.1

D. N. L. RALPHS, B.CHIR., F.R.C.s., Senior Registrar in Surgery

H. S. JACOBS, M.D., M.R.C.P., Senior Registrar in Medicine and Honorary Research Associate (Present appointment: Senior Lecturer in Gynaecological Endocrinology, St. Mary's Hospital Medical School, London
W2 1PG)
Prolactin concentrations in 113 women with tumours of the breast. $=$ Premenopausal women with benign lesions. $\boldsymbol{\Delta}=$ Premenopausal women with malignant lesions. $\mathrm{O}=$ Postmenopausal women with benign lesions. $\Delta=$ Postmenopausal women with malignant lesions.

distribution of prolactin levels between the various groups, with a preponderance of cases of hyperprolactinaemia (defined as exceeding the mean +2 S.D. of normal subjects) in the group of premenopausal women with benign lesions. Since the distribution of hyperprolactinaemic patients in the various groups was not normal no attempt was made to compare the means of the four groups. On statistical analysis of the data, using the Wilcoxon rank test (non-parametric) for comparison of two asymmetrical groups, no significant difference was found in prolactin levels when comparing the benign with the malignant group $(P>0.6)$. The incidence of hyperprolactinaemia was significantly higher, however, in the premenopausal than in the postmenopausal group $(P<0.01)$. This difference was not evident when using the Kruskal-Wallis test for one-way analysis of variance in the four smaller individual groups. This test does not give any information, however, about differences between pairs of groups.

Prolactin concentrations which were greatly increased ( $>25 \mathrm{ng} / \mathrm{ml}$ ) were found in six patients with benign lesions of the breast and in one patient with cancer. The details of those patients with benign lesions are shown in the table. Of the four hyperprolactinaemic premenopausal patients three had fibro-

Details of Patients with Benign Lesions of the Breast associated with Greatly Increased Prolactin Levels

\begin{tabular}{|c|c|c|c|c|}
\hline $\begin{array}{l}\text { Case } \\
\text { No. }\end{array}$ & $\begin{array}{c}\text { Age } \\
\text { (Years) }\end{array}$ & $\begin{array}{l}\text { Menopausal } \\
\text { Status }\end{array}$ & $\begin{array}{l}\text { Histological Diagnosis } \\
\text { of Breast Lesion }\end{array}$ & $\begin{array}{c}\text { Prolactin } \\
\text { Concentration } \\
(\mathrm{ng} / \mathrm{ml})\end{array}$ \\
\hline $\begin{array}{l}1 \\
2 \\
3 \\
4 \\
5 \\
6\end{array}$ & $\begin{array}{l}31 \\
23 \\
27 \\
27 \\
49 \\
59\end{array}$ & $\begin{array}{l}\text { Premenopausal } \\
\text { Premenopausal } \\
\text { Premenopausal } \\
\text { Premenopausal } \\
\text { Postmenopausal } \\
\text { Postmenopausal }\end{array}$ & $\begin{array}{l}\text { Fatty tissue with fibrosis } \\
\text { Fibroadenoma } \\
\text { Fibroadenoma } \\
\text { Fibroadenoma } \\
\text { Duct ectasia and fibrosis } \\
\text { Duct ectasia and fibrosis }\end{array}$ & $\begin{array}{r}>100 \\
>100 \\
>100 \\
25 \\
71\end{array}$ \\
\hline
\end{tabular}


adenomas and one (who was taking the oral contraceptive) had a lump caused by fatty tissue and fibrosis. In contrast, prolactin concentrations were not raised in the 20 other premenopausal patients in this series who had fibroadenomas.

Both postmenopausal patients with benign lesions and raised prolactin concentrations had duct ectasia. This histological diagnosis was also made in two other postmenopausal patients whose prolactin concentrations were normal. The one patient with malignant disease and hyperprolactinaemia had an adenocarcinoma.

\section{Discussion}

When the patients with benign and malignant diseases of the breast were divided into groups according to their reproductive status there was a significant difference in the incidence of hyperprolactinaemia between the whole group of premenopausal patients and the whole group of postmenopausal patients. It therefore seems important to consider the reproductive status in any study relating to prolactin measurements in patients with benign and malignant disease of the breast.

Our results do not support the theory of an aetiological relationship between hyperprolactinaemia and breast cancer. Furthermore, analysis of the histological findings in the benign lumps in the patients with and without hyperprolactinaemia does not provide support for an aetiological role of prolactin in this condition either.

Finally, it remains to consider the cause of the hyperprolactinaemia in the seven patients who had levels above $25 \mathrm{ng} / \mathrm{ml}$. Pituitary tumours in these patients were unlikely since skull $x$-ray examinations showed nothing abnormal. None was receiving tranquillizers or other drugs thought to raise prolactin levels. Stress, both physical and psychological (Frantz et al., 1972; Friesen et al., 1972), can raise prolactin concentrations. Possibly the cause of the hyperprolactinaemia in these patients was the psychological stress associated with the fear of surgery for a lump in the breast. These findings emphasize the need for a strictly matched control group in evaluating hormonal profiles in patients with cancer. We suggest that in the case of carcinoma of the breast patients with benign breast disease form the most suitable group for comparison.

S. Franks is supported by a Saltwell Research Fellowship from the Royal College of Physicians. We thank Mr. R. S. Handley for his co-operation and the morbid anatomy department of the Bland Sutton Institute of Pathology, Middlesex Hospital Medical School, for the histological diagnoses.

Requests for reprints should be addressed to S. Franks, Department of Nuclear Medicine, Thorn Institute of Clinical Science, Middlesex Hospital Medical School, London W.1.

\section{References}

Boyns, A. R., et al. (1973). European fournal of Cancer, 9, 99.

Frantz, A. G., Kleinberg, D. L., and Noel, G. L. (1972). Recent Progress in Hormone Research, 28, 527.

Friesen, H., et al. (1972). In Prolactin and Carcinogenesis, ed. by A. R. Boyns and K. Griffiths. Cardiff, Alpha Omega Alpha Press.

Lancet. (1974). 1, 908 .

Mittra, I., Hayward, J. L., and McNeilly, A. S. (1974). Lancet, 1, 889.

Murray, R. M. L., Mozaffarian, G., and Pearson, O. H. (1972). In Prolactin and Carcinogenesis, ed. A. R. Boyns and K. Griffiths, p. 158. Cardiff, Alpha Omega Alpha Press.

Sinha, Y. N., et al. (1973). Fournal of Clinical Endocrinology and Metabolism, 36, 509 .

\title{
Cutaneous and Ocular Reactions to Practolol
}

\author{
R. H. FELIX, F. A. IVE, M. G. C. DAHL
}

British Medical fournal, 1974, 4, 321-324

\section{Summary}

A total of 21 patients suffering from drug-induced rashes from practolol have been seen over the past two years. The clinical manifestations varied, with the morphological appearances of the rash resembling those of eczema, lupus erythematosus, lichen planus, and a highly characteristic toxic erythematous psoriasiform eruption. Persistent ocular damage was a feature in three cases.

\section{Introduction}

Practolol is a cardioselective beta-blocking agent with intrinsic sympathomimetic activity (Barrett, 1971) used in the treatment of various cardiovascular disorders, particularly angina pectoris and cardiac arrythmias. Early clinical trials with practolol did

\footnotetext{
University Department of Dermatology, Royal Victoria Infirmary, Newcastle upon Tyne NE1 4LP

R. H. FELIX, M.R.C.P., Senior Registrar in Dermatology

M. G. C. DAHL, M.R.C.P., Consultant Dermatologist

Dryburn Hospital, Durham DH1 5TW

F. A. IVE, M.R.C.P., Consultant Dermatologist
}

not reveal any adverse cutaneous reactions (Sandler and Clayton, 1970; George et al., 1970), but the number of patients treated was small and each trial lasted only 12 weeks. In a survey of 2,100 patients who were taking practolol seven patients were found to have developed a micropapular, eczematous, or urticarial rash (Wiseman, 1971). Practolol can also induce a syndrome similar to lupus erythematosus (L.E.) the symptoms of which are fever, polyarthritis, and an erythematous rash, associated with positive results of tests for L.E. cells and antinuclear factor (Raftery and Denman, 1973).

Since the report of a patient with exfoliative dermatitis produced by practolol (Rowland and Stevenson, 1972) an increasing number of patients have been referred to us with a rash which was later found to be caused by this drug. Though some of the patients presented with eczematous or lichenoid rashes most presented with a distinctive psoriasiform eruption which, we feel, produces an easily recognizable diagnostic picture.

\section{Patients}

Twenty-one patients (nine men, 12 women) ranging in age from 45 to 78 years were seen in the skin department. Each patient was taking 100-600 mg of practolol daily (see table) for either angina pectoris or supraventricular tachycardia. Most patients were taking also a combination of other drugs, usually a diuretic, a tranquillizer, and an antihypertensive agent. The duration of treatment with practolol before the onset of the rash 